\title{
LIBROS DEL SIGLO XVI EN LA BIBLIOTECA DEL LABORATORIO DE ARTE: I. TRATADOS DE ARQUITECTURA
}

\author{
por JAVIER LOBATo DOMÍNGUEZ
}

En el artículo se catalogan y estudian los tratados de arquitectura impresos en el siglo XVI que se conservan en la Biblioteca del Departamento de Historia del Arte de Sevilla. Se analiza la historia bibliográfica de las obras y su contribución a la teoría y práctica artística del momento. Finalmente se incluyen los asientos catalográficos de cada libro redactados siguiendo las reglas del Ministerio de Cultura: Dirección General del Libro y Bibliotecas (1985-1988), y la ISBD (A).

This article catalogues and studies the 16th century printed architectural treatises in the library of the Department of Art History in Seville. The bibliographical history of these works is analysed, as is their contribution to the artistic theory and practice of the period. Finally, the catalogue reference is given for each book, following the norms laid down by the Book and Library Department of the Spanish Ministry of Culture (1985-1988), as well as the ISBD (A)

Desde la fecha de fundación del Laboratorio de Arte una de las preocupaciones principales de su entonces director y profesorado fue la de dotar a la reciente institución de medios materiales que posibilitasen el desarrollo de una labor científica con rigor metodológico y especial atención a las fuentes. Será desde esta perspectiva como se explique la formación de una importante biblioteca que desde su origen se vio enriquecida por la donación y adquisición de fondos bibliográficos antiguos de gran valor ${ }^{1}$.

1. Algunas noticias sobre los orígenes del Departamento de Arte y su fundador en: M. ${ }^{\text {a José del }}$ Castillo Utrilla: "Don Francisco Murillo Herrera”, Laboratorio de arte, n.․ 2. Sevilla, 1989, págs. 267-277. Y también en: Jesús M. "Palomero Páramo: "El archivo de Protocolos Notariales y la Historia del Arte en Sevilla", prólogo de Fuentes para la Historia del Arte Andaluz I: Noticias de Pintura (1700-1720) / Fernando Quiles García. Sevilla, 1990, págs. 9-43. 
Estos fondos bibliográficos anteriores a 1801 constituyeron la sección de antiguos y raros de la Biblioteca del Laboratorio de Arte, formada hoy en día por unos trescientos impresos, con algún que otro manuscrito, que abarcan desde el siglo XVI al XVIII.

Durante los últimos años hemos abordado la catalogación normalizada y estudio de estos libros, de los que ahora ofrecemos en este artículo un primer avance referente a las obras del siglo XVI. Son en total veinte los libros de este período que se conservan en la Biblioteca del Laboratorio de Arte, número reducido de impresos que sin embargo adquieren importancia al formar un conjunto coherente y privilegiado por su forma y contenido; siendo buena muestra de algunos de los principales temas de la historiografía artística del Renacimiento y el Manierismo: Tratados de Arquitectura, Libros de erudición arqueológica, textos de interés iconográfico con abundante ilustración, etc.

Hemos dividido en cinco apartados temáticos las obras catalogadas y será este el esquema que seguiremos en el estudio bibliográfico preliminar que aquí ofrecemos. Si bien por razones de espacio sólo incluiremos en este número de la revista el apartado I. Tratados de Arquitectura (11 libros), dejando los restantes (Perspectiva y Geometría, Anticuarios y eruditos, Iconografía, varia) para un próximo número.

\section{TRATADOS DE ARQUITECTURA}

El tratado de arquitectura responde a un tipo de literatura científica de larga tradición en Europa. La primera obra que se ha conservado de estas características es el archiconocido tratado de Vitrubio. Partiendo de esta obra se consolida durante los siglos XV y XVI la teoría arquitectónica moderna, primero a través de la asimilación de sus contenidos por León Battista Alberti y poco después al imprimirse el texto vitrubiano hacia 1486.

\section{Leone Battista Alberti "De Re Aedificatoria" (1485)}

Alberti, paradigma del nuevo hombre renacentista, al escribir el tratado " $D e$ re aedificatoria" (1443-1452) hará suyas las ideas de Vitrubio, asentando en ellas su defensa de la nobleza y perfección del Arte Clásico. Legitimará teóricamente de esta forma la revolución de la lingüística arquitectónica iniciada, en el terreno práctico, por Brunelleschi ${ }^{2}$.

2. TAFURI, Manfredo: La arquitectura del humanismo. Madrid: Xarait, 1982, págs. 15-18. Y sobre todo: Franco Borsi: Leon Battista Alberti: opera completa. Milano: Electa, 1973, págs. 199 210 . 
El tratadista utiliza a Vitrubio, pero no lo compendia servilmente. En su afán de racionalizar la nueva gramática clásica somete a análisis arqueológico los restos de la antigüedad romana, constatando las contradicciones entre la teoría vitrubiana de corte helenístico y la práctica latina. El conocimiento directo de los monumentos antiguos de Roma queda demostrado en Alberti a través de su libro "Descriptio urbis Romae" (1433), iniciador de un género de literatura arqueológica que tendrá gran éxito.

Dividirá su tratado en diez libro como el texto vitrubiano, distinguiendo los principios de la Arquitectura con los conceptos de aquel: firmitas, utilitas y venustas; e incluso utiliza para narrar la obra el estilo directo. Pero todas estas coincidencias son meramente externas el tratado de Alberti es muy diferente de la obra de Vitrubio. El "yo" de Alberti en su tratado es -como ha señalado Françoise Choay ${ }^{3}$ - eminentemente especulativo, índice de una larga reflexión sobre el tema, el "yo" vitrubiano es el del mundano y pragmático artífice que recoge en su escrito una tradición técnica que para la fecha resultaba ya anticuada: la del helenismo tardío. Alberti será por tanto el verdadero compendiador y teórico de la arquitectura romana imperial. A ello se debe añadir su preocupación por el edificio como parte integrante del paisaje y su interés por el urbanismo, con notas de gran modernidad.

El idioma en el que está redactado el tratado -el latín-, el contenido, teórico y especulativo más que doctrinal; y la carencia de dibujos o grabados ejecutados para ilustrar el texto condicionaron su difusión.

La difusión manuscrita del texto entre 1452 y 1485 debió ser escasa, y las referencias a él por otros arquitectos y tratadistas (Filarete, Manetti, Francesco di Giogio...) indican que "la obra se conocía más de oídas que por una lectura a fondo" ". El libro se imprimió por primera vez en 1485 por Nicolò di Lorenzo Alemanno en Florencia, trece años después de la muerte del autor. Debemos esperar al siglo siguiente para que la obra conozca sucesivas reediciones y se efectúen sus primeras traducciones, algunas ilustradas, que contribuyeron al mejor conocimiento de las teorías de Alberti.

Las primeras ediciones del De re aedificatoria en el siglo XVI fueron las de París (1512) y Estrasburgo (1541), que junto con la primera de 1485 son las tres únicas publicaciones latinas de la obra. Pietro Lauro la tradujo al italiano en 1546 (Venecia: Vincenzo Valgrisi. Reimp. en 1565). Poco después en 1550 Cosimo

3. CHOAY, Fraçoise: "Le De re aedificatoria comme texte inaugural", en Les traités d'architecture de la Renaissance: actes du colloque tenu à Tours du l. er au 11 juillet 198I. - Paris: Picard, 1988 págs. 83-90.

4. SCHLOSSER, Julius: La literatura artística: manual de fuentes de la historia moderna del arte. Madrid: Cátedra, 1986, pág. 121. 
Bartoli publica su versión italiana en Florencia, siendo esta la primera edición ilustrada de la obra si bien debemos señalar que ya existía un códice con dibujos y traducción italiana del texto por Damiano Pietri fechado en 1538 (Biblioteca Municipale de Reggio Emilia, Cod. Mss. Vari G.3.).

Jean Martín, secretario de Maximiliano Sforza y del cardenal de Lenoncourt, fue uno de los humanistas que más hicieron por la difusión del clasicismo arquitectónico en la Francia del siglo XVI, y él se encargó de traducir al francés la obra de Alberti, que se imprimió en París en 1553.

La última traducción del tratado albertiano que se realizó en el siglo XVI es la que ahora catalogamos: la española impresa por Alonso Gómez en Madrid en 1582 (Cat. n. $\left.{ }^{\circ}\right)^{\text {s. }}$.

Se relaciona la traducción española en 1582 con el movimiento de renovación de los métodos de enseñanza de la arquitectura que por esas fechas propugnaba en Madrid Juan de Herrera (1532-1597). Este arquitecto fundó en la capital, a instancias del rey, una Academia de Matemáticas en la que se pretendía existiera una cátedra de Arquitectura ${ }^{6}$. Para dicha institución se necesitaban textos técnicos y es significativo que en el año en que fue proyectada, 1582, se publicarán en Madrid y Alcalá de Henares las primeras traducciones españolas de Alberti y Vitrubio.

Francisco Lozano, alarife de la villa de Madrid, fue quien se interesó por hacer traducir e imprimir el De re aedificatoria, actuando como editor. Inició los trámites (petición de privilegio y licencias) en 1578, y aún tardaría cuatro años en solventar los problemas legales y económicos que le permitieron entregar la obra al impresor real, Alonso Gómez. El Consejo encargó a Juan de Herrera la censura del texto, y éste en su contestación, tras señalar la utilidad del libro, acertó al exponer el peor defecto de la obra: la pésima traducción castellana que habían ejecutado para Lozano. Es probable que fuera el propio hijo del alarife quien basándose en la traducción italiana de Cosme Bartoli (Florencia, 1550 y $1565)$, la vertiera con graves errores al español. Herrera afirma: "Aunque tenemos muchas malas traducciones en nuestra lengua, ninguna tan bárbara como la de Alberti. En una partes no hay gramática: en otras ni aun se halla sentido" 7 .

5. No fue la relativamente tardía impresión de Gómez la primera muestra de la presencia de las ideas de Alberti en nuestro país, pues ya en 1550 un anónimo miembro del círculo cortesano del todavía príncipe Felipe, escribió un tratado de Arquitectura dedicado a este gran mecenas, basándose para ello en el texto del De re aedificatoria, ver Fernando Marías: El largo siglo XVI: los usos artísticos del Renacimiento español. - Madrid: Taurus, 1989. pág. 71.

6. Ibidem, pág. 511 y 524. También Eugenio Llaguno y Amirola y Juan Agustín Ceán Bermúdez (adiciones): Noticias de los arquitectos y arquitectura de España desde su restauración. - Madrid: Turner, 1977. IV. Vol. II, Págs. 141-147.

7. LLAGUNO, Eugenio y AMIROLA: Id. Vol. III, pág. 31. 
La edición española no está ilustrada, y únicamente en la portada aparece el grabado. Este es de tipo arquitectónico reproduciendo una portada con el cuerpo inferior articulado por columnas de orden corintio y el superior ocupado por un amplio ático que se remata con un escudo de armas. El diseño de la xilografía está inspirado en las portadas "dilicate" XI y XIIII del Extraordinario libro di Architettura de Sebastián Serlio, e influyó en artistas españoles como Martínez Montañés y Alonso Cano que utilizaron su traza en algunos retablos ${ }^{8}$.

El libro fue expurgado en el siglo XVII, tachándosele quince líneas en la pág. 220 y doce en la 221. Existe en el ejemplar que se conserva en la Biblioteca Nacional de Madrid (B.A. 2948) una nota manuscrita en portada que se refiere a este hecho: "Este libro está visto y expurgado, conforme al nuebo cathalogo y expurgatorio del S. Oficio en Madrid 24 de jullio (1685?) el doctor Joan del Llano (rúbrica)". Seguramente se refiera al índice de 1640 , publicado por el inquisidor general Antonio de Sotomayor.

\section{Marco Lucio Vitrubio Polion “De Arquitectura Libri Decem” (1486/.92?).}

Vitrubio estará en la base de toda especulación teórica sobre arquitectura del Renacimiento. Sus Diez libros de arquitectura, escritos en la segunda mitad del siglo I a.C. (hacia el año 28-27 a.C.), conocieron una importante difusión manuscrita, a través de códices monásticos, en la Baja Edad Media ${ }^{9}$. La obra se recuperó para la teoría artística cuando los humanistas y algunos arquitectos del siglo $\mathrm{XV}$ italiano, rescatan del olvido varios códices medievales, comentándolos y usando sus oscuros términos latinos como justificación de las renovadoras ideas que propugnaban. La difusión del texto vitrubiano se aceleró tras su primera edición impresa, la del gramático Johannes Sulpitius Verulanus (Roma: Heroldt, 1486/92?), que se publicó poco después del tratado de Alberti. El impacto que produjo la obra de Vitrubio en la teoría arquitectónica y la crítica filológica del siguiente siglo, se percibe en el gran número de ediciones que vieron la luz antes de 1600 -más de veinticinco ${ }^{10}$-, muchas de ellas comentadas, y en la traducción del tratado al italiano (1521), francés (1547), alemán (1548) y español (1582).

8. PALOMERO PARAMO, Jesús Miguel: "La influencia de los tratados arquitectónicos de Serlio y Palladio en los retablos de Martínez Montañés", en Homenaje al profesor Dr. Hernández Díaz. -Sevilla: Universidad, 1982, págs. 503-525. Ver pág. 507.

9. CERVERA VERA, Luis: El códice de Vitrubio hasta sus primeras versiones impresas. Madrid: Instituto de España, 1978.

10. Lista completa de las ediciones en: John Bury: "Renaissance architectural treatises and architectural books: a bibliography", en les traités d'architecture de la Renaissance...op. cit. págs. 501-502. 
La primera edición de Vitrubio que catalogamos, la que imprimió en Lyon Jean de Tournes el viejo en 1552 (Cat. n. ${ }^{\circ}$ 2), constituye la versión definitiva del tex to vitrubiano comentado por Guillaume Philander. Conocemos bien la vida de este eminente filólogo francés a través de las noticias que aporta su biógrafo Philibert de la Mare "I. Probablemente en Venecia Philander inicia de forma sistemática el estudio del texto vitrubiano, trabajo que continúa en Roma desde 1539. En esta última ciudad entra a formar parte de la Academia de la Virtud, institución creada por un grupo de eruditos, nobles y arquitectos (Claudio Tolomei de Siena, Bernardino Maffei, Agostino de Landi, Vignola...) con la idea de revisar a fondo el tratado de Vitrubio y limpiar los errores acumulados por códices y malas ediciones ${ }^{12}$. Philandro publicará su comentario en 1544 poco antes de regresar a Francia. Fue impreso en un minúsculo dieciseisavo con unas pocas ilustraciones, gozando de gran popularidad en los ambientes cultos de Roma.

El comentario de Philander se imprimió conjuntamente con el texto de Vitrubio -versión latina de Giocondo- en Estrasburgo por W.H. Ryff en 1550. Pero la edición más cuidada y difundida, con la supervisión del propio Philander, fue la que Jean de Tournés publicó en Lyon (1552) (Cat. n.ํㄹ 2), usando también el texto revisado de Fra Giocondo. Para la edición lionesa se tallaron setenta y siete nuevos tacos xilográficos, cuyo diseño ha sido atribuido a Serlio ${ }^{13}$, si bien en ella el interés del texto predomina sobre las ilustraciones.

El tratado de Vitrubio, al margen de las cultas versiones latinas de los filólogos, se fue popularizando por medio de las traducciones que proliferaron en el siglo XVI. A las Italianas de Cesariano (1521), Francesco Lutio Durantino (1524), Giovanni Battista Caporali (1536), Daniel Barbaro (1556, con ilustraciones de Palladio), y Giovanni Antonio Rusconi (1590), se deben añadir la francesa de Jean Martín (1547) y la alemana de Walther Hermann Ryff (1548). Finalmente en 1592 se edita, póstumamente, la traducción castellana de Miguel de Urrea en Alcalá de Henares (Cat. n. ${ }^{\circ}$ ).

11. MARE, Philibert de la: De vita moribus et scriptis Guillelmi Philandri Castillonii civis Romani Epistola. (1667), cito a través de Dora Wiebenson: "Guillelmi Philander's annotations to Vitruvius", en Les traités d' architecture de la Renaissance: actes du colloque tenu à Tours du $1 .{ }^{\text {er }}$ au 11 juillet 1981. op. cit. págs. 67-74. Ver en el repertorio: Los tratados de arquitectura; de Alberti a Ledoux. - Madrid: Hermann Blume, 1988, los números I-14 y I-17 (págs. 63-66) redactados por la misma autora.

12. SCHLOSSER, Julius: La literatura artística: manual de fuentes de la Historia Moderna del Arte, op. cit. pág. 227-228.

13. BELL DINSMOOR, William: "The literary remains of Sebastiano Serlio", en The Art Bulletin T. XXIV (1942), págs. 55-91 y 115-154. Ver pág. 76. 
Antes de que Urrea publicara su versión de 1582, existieron varios intentos de dar a conocer el texto entre los arquitectos españoles. Es bien conocida la traducción de Lázaro de Velasco realizada entre 1554-1564 y de la cual se conserva el manuscrito. También en estas fechas centrales del siglo Hernán Ruiz el joven tradujo el libro primero de Vitrubio en su Manuscrito de Arquitectura ${ }^{14}$. Todo ello indica que las ediciones italianas y francesas del tratado de Vitrubio circulaban fácilmente por España desde principios de siglo, como también se demuestra en la influencia que el tratadista romano ejerce en Diego de Sagredo ${ }^{15}$. El estudio de los inventarios de bibliotecas confirma esta presencia ${ }^{16}$. La traducción de Urrea sorprende quizá por su fecha tardía, debiéndose relacionar, como la ejecutada del libro de Alberti, con el movimiento renovador de la Academia de Matemáticas de Madrid.

Miguel de Urrea debió traducir los libros de Vitrubio en la década de los sesenta; su muerte, acaecida entre 1565 y 1568, impidió que iniciara personalmente los trámites legales para imprimir el manuscrito que, sin embargo, dejó preparado para las prensas. Su viuda Mari Bravo solicitó el privilegio real de impresión, obteniéndolo por diez años en 1569. Tuvieron que pasar trece largos años desde esta fecha para que el texto de Urrea se imprimiera en el taller tipográfico de Juan Gracián en Alcalá de Henares.

Juan Gracián, uno de los más activos impresores de Alcalá durante la segunda mitad del siglo XVI (1568-1588), corrigió la versión de Urrea, proclamándose en la dedicatoria autor único de la traducción. La tardanza con la que se imprimió la obra, puede justificarse por motivos económicos, la extensión del libro es de tipo medio 143 hojas, pero la ilustración es muy abundante 126 xilografías, y los grabados se tallaron específicamente para esta edición, encareciendo el coste del libro. Las prensas de Alcalá pasaban en estos años por una crisis de calidad, quedando muy atrás la época dorada de los Brocar y sus elegantes ediciones. El resultado final fue un impreso donde la buena tipografía empleada desmerece ante las algo toscas ilustraciones, todo ello (letrerías y grabados) estampado con

14. GARCIA MELERO, José Enrique: "Las ediciones españolas de De Architectura de Vitruvio", en Fragmentos: Revista de Arte n.o 8 y 9 (número doble monográfico sobre Vitruvio) (1986), págs. 102-131.

15. SIERRA CORTES, José Luis: "Diego de Sagredo y Vitruvio", en Fragmentos: revista de Arte n. ${ }^{\circ} 8$ y 9 op. cit. págs. 4-19.

16. Algunos de los propietarios de las obras de Vitrubio en la España del siglo XVI fueron: Diego de Sagredo, Lázaro de Velasco, Miguel de Urrea, Juan Bautista de Toledo, Juan de Herrera, Monegro, El Greco, Diego Hurtado de Mendoza, Juan Bernal Díaz de Luco, Felipe II, Pedro Fajardo y Córdoba (tercer Marqués de los Vélez), y Benito Arias Montano. Un grupo de lectores bastante definido: profesionales de la arquitectura, mecenas e intelectuales. 
descuido (algún grabado aparece invertido y otros rotos) en un papel que empeora conforme se avanza en los cuadernillos ${ }^{17}$.

Urrea utilizó para realizar su traducción la versión latina comentada por Philandro (Lyon, 1552), pero no pretende hacer una edición crítica, ni le interesa la erudición filológica, su intención era divulgar el texto entre maestros de obra y modestos profesionales de la arquitectura; personas que pertenecen al mismo estrato cultural que el traductor.

Terminemos este comentario con una referencia a las ilustraciones de la edición de Urrea-Gracián. Son, como ya dijimos, 126 grabados xilográficos de sencillo diseño y tosca ejecución, orientados a facilitar la comprensión general del texto. La tradición iconográfica de estas ilustraciones aún no ha sido establecida en rigor: Luis Moya las ve derivadas de las que se emplearon en la edición de Gianbattista Caporali, afirmando que no están influidas por las de Cesariano, - ni por las de Palladio-Barbaro. No opinan así Fernando Marías y Agustín Bustamante que las relacionan con Fra Giocondo, Cesariano, Durantino y Barbaro ${ }^{18}$. Por nuestra parte podemos añadir que encontramos una clara dependencia de los diseños que Juan Gracián incluye en la edición española con los de Cesariano (1521), e incluso con los de Philander (1552); si bien, las cuidadas imágenes de gran formato del italiano se reinterpretan usando el "modo" popular (empleado ya en las versiones de Durantino y Caporali), obteniéndose resultados mucho más sumarios.

\section{Sebastiano Serlio "Regole de Architecttura" (1537-1575)}

Serlio (1475-1554) inicia la tratadística arquitectónica italiana del siglo XVI. Sus libros modificarán el contenido y forma habitual de los escritos sobre este arte. A la presentación teórica, con extensa literatura, de Alberti o Vitrubio él opone una serie de compendios temáticos profusamente ilustrados, con carácter más de manuales prácticos que de tratados teóricos.

La figura de este pintor y arquitecto boloñés es, posiblemente, una de las más controvertidas de quinientos europeo. Mejor conocido por su obra escrita y gráfica que por la escasa labor construida, fue en su tiempo exaltado y denostado con igual pasión. Francisco I de Francia lo invitó a su corte de Fontainebleau. Arqui-

17. He consultado dos ejemplares de la obra, además del que catalogamos (Cat. n. ${ }^{\circ} 3$ ), en la Biblioteca Nacional: Sign. U. 8567, y R. 25536. Todos están impresos en un papel de mala calidad (la pasta apenas se refinó) a partir de la mitad del libro. El de la B.N. U 8567 responde a otra tirada,

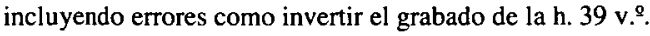

18. GARCIA MELERO, José Enrique: "Las ediciones españolas de De Architectura de Vitruvio", en Fragmentos: revista de Arte, n. 8 y 9. op. cit. págs. 112-113. 
tectos de Francia, España, Hispanoamérica, Alemania y los Países Bajos imitaron reiteradamente los diseños de su tratado. En Italia fue donde más duras críticas se le hicieron, así la afirmación de Giovan Paolo Lomazzo de que sus obras produjeron "más arquitectos mediocres que pelos tenía en la barba", Vasari y Lomazzo le acusaron de haber utilizado de forma plagiaria el material que heredó en 1527 de su "maestro" Baldassare Peruzzi (1481-1536) ${ }^{19}$. La crítica artística posterior relativizó sus aportaciones al contrastar el utilitarismo de los tratados serlianos con la genialidad teórico-práctica de la obra de Palladio.

En la primera edición veneciana del Libro cuarto, Serlio establece el esquema que pretende dar a su manual de reglas de Arquitectura en siete libros. La aparición de un códice con una nueva obra de Serlio: Della castramentatione di Polibio ridutta in una cittadella murata, ha llevado a la crítica actual a pensar que este escrito pertenece a la serie general de las Regole de architectura y lo han denominado por tanto el Octavo libro de arquitectura de Sebastiano Serlio ${ }^{20}$. Resumiendo, las reglas arquitectónicas escritas por Serlio se reúnen en nueve libros (ocho y uno extraordinario).

La gran originalidad de la obra de Serlio radica tanto en la intención como en la estructura formal que presenta. En las palabras iniciales del libro IV, el primero en ser publicado y el que más aspectos teóricos incluye, se afirma que la obra no sólo se dirige a "los elevados y subtiles ingenios", sino para que "los medianos puedan ser dellas participantes" ${ }^{21}$. Serlio escribe sus normas para el profesional no versado en latín, y para el diletante aficionado a la arquitectura. Para ello adopta una forma novedosa, en vez de un texto continuo, con o sin ilustraciones intercaladas, ofrece una serie de imágenes con breve comentario explicativo. El diseño gráfico logra comunicar más información que el argumento textual ${ }^{22}$.

19. Recogemos la cita de Lomazzo de: J. R. Hale (dir): Enciclopedia del Renacimiento italiano. Madrid: Alianza, 1984. Voz "Serlio, Sebastiano" en págs. 354-355 (redactada por Caroline Elam). Sobre la influencia de Perezzi en la obra de Serlio y las exageradas críticas de Lomazzo y Vasari ver: Howard Burns: "Baldasare Peruzzi and sixteenth-century architectural theory", en les traités d'architecture de la Renaissance... op. cit. págs. 207-226. También: Christof Thoenes: "Serlio e la trattratistica", prólogo de Sebastiano Serlio: [atti dei] Sesto Seminario Internazionale di Storia dell'Architettura: Vicenza 31 agosto - 4 settembre 1987. Milano: Electa, 1989. pp. 9-18. Y Julius Schlosser: la literatura artística: manual de fuentes dela historia moderna del arte. op. cit. pág. 350.

20. FIORE, Francesco Paolo: "Sebastiano Serlio e il manoscritto dell'Ottavo Libro", en Sebastiano Serlio: Sesto Seminario... op. cit. págs. 216-221.

21. Tercero y quarto libro de Architectura de Sebastian Serlio boloñes 1 ...traduzido de Toscano en Romance Castellano por Francisco de Villalpando architecto. - Toledo: Juan de Ayala, 1552. Lib. IV pág. 4.

22. NAN ROSENFELD, Myra: "Sebastiano Serlio's contributions to the creation of the modern illustrated architectural manual”, en Sebastiano Serlio: Sesto Seminario... op. cit. págs. 102-110. 
La valoración que Serlio hace de la imagen en sus libros va más allá de la simple elección formal, su teoría de la arquitectura prima los valores perceptuales sobre los constructivos. La apariencia externa, el juego visual, la legitimación de la perspectiva, todo nos indica que estamos ante un nuevo tipo de arquitecto, un profesional del diseño proyectual más que un maestro de obras. En este sentido el tratado de Serlio destaca por el uso renovador de los recursos gráficos, usa dibujos polivalentes o de uso múltiple -igual sirven para una portada, que para una ventana o una fuente-; en sus alzados, al suprimir los límites laterales, establece un principio de seriación que, además de economizar medios, da libertad de elección al que pretenda emplearlos. Será él y no Palladio, como a veces se ha afirmado, quien primero utilice la transparencia de elementos constructivos para permitir ver los situados tras ellos ${ }^{23}$.

Buena prueba de la aceptación que la obra de Serlio tuvo en los medio profesionales son las 56 ediciones del tratado durante los siglos XVI y XVII ${ }^{24}$, además del hecho de haber sido traducidos, todos o algunos de sus textos, al holandés, alemán, francés, español, latín e inglés.

El panorama bibliográfico de las diferentes ediciones de los libros de Serlio es muy complejo. Son al menos siete las unidades temáticas diferentes (libros IV, VII y Extraordinario) que unas veces se publican en solitario, otras por parejas (libros I y II, III y IV) y ocasionalmente en colecciones casi completas (libros I-V y el extraordinario) ${ }^{25}$. La viajera vida del autor condicionó la publicación separada en Italia y Francia de las primeras ediciones de algunos libros. Por otra parte el rápido interés que despertó la obra, llevó a algunos artistas a arriesgarse

23. Sobre las teorías arquitectónicas de Serlio ver: ARNAU AMO, Joaquín: la teoría de la Arquitectura en los tratados; v.III: Filarete, Di Giorgio, Serlio, Palladio. - Madrid: Tebar Flores, 1988, págs. 139-175. Y THOENES, Christof: "Serlio e la trattatistica", prólogo de Sebastiano Serlio: Sesto Seminario... op. cit. págs. 9-18.

SAINZ, Jorge en : El dibujo de Arquitectura: teoría e historia de un lenguaje gráfico. Madrid: Nerea, 1990, pág. 96, atribuye a Palladio la novedad gráfica de hacer transparentes algunos elementos arquitectónicos.

24. Ver lista completa de las ediciones en: BURY, John Bernard: "Serlio: some bibliographical notes”, en Sebastiano Serlio: Sesto Seminario... op. cit. págs. 92-101. Apéndice en págs. 100-101.

25. Los libros VI y VIII nunca se imprimieron, conservándose varios manuscritos de ellos en la Staatsbibliothek de Munich y en la Avery Library de Nueva York. Ver el estudio del libro VI en: William Bell Dinsmoor: "The Sebastiano Serlio", op. cit. págs. 115-141. Sobre el libro VIII: Francesco Paolo Fiore: “'Sebastiano Serlio e il manoscritto dell'Ottavo Libro", en Sebastiano Serlio: Sesto Seminario... op. cit. págs. 216-221. Los códices de estos libros y el del séptimo se los compró en Lyon al propio Serlio el anticario Jacopo Strada, que sólo publicaría el libro VII en Franckfurt (1575). Ver Dirk Jacob Jansen: "Jacopo Strada editore del Settimo Libro", en Sebastiano Serlio: Sesto Seminario... op. cit. págs. 207-215. Y Julius Schlosser: La literatura artística: manual de fuentes de la historia moderna del arte, op. cit. pág. 350. 
a traducir y editar los libros que iban saliendo, con una sorprendente prontitud (Pieter Coecke y Francisco Villalpando). John Bernard Bury ha estudiado este intrincado mundo de las diferentes impresiones del tratado ${ }^{26}$.

Tras publicar en Venecia los libros IV y III Serlio continúa editando la obra en Francia, imprimiendo los libros I y II en París en el taller de Iehan Barbe en 1545. Antes de esta fecha Pieter Coecke ya había traducido (al holandés, alemán y francés) y editado el libro IV en Amberes (1539-1542).

El número cuatro de nuestro catálogo es por tanto la primera edición de los libros I y II (París: Iehan Barbe, 1545). Los dos libros se presentan como unidad, con una sola portada y numeración correlativa de páginas. El texto es bilingüe diferenciando tipográficamente los párrafos italianos (humanística minúscula cursiva) de los franceses (humanística minúscula redonda). La traducción francesa es de Jean Martín, que como vimos también tradujo a Vitrubio y Alberti. El libro primero estudia la geometría y el segundo la perspectiva, en ambos el contenido teórico rechaza la habitual estructura hipotético-deductiva que presentaba la tratadística matemática sobre estos temas, para presentar una estructura pragmática, en la que se privilegia los problemas formales que dichas ciencias pueden resolver al arquitecto ${ }^{27}$. Las numerosas ilustraciones ejemplifican cada apartado, aclarando su contenido. En el libro primero se incluyeron 81 diseños geométricos algunos como solución arquitectónica; en el segundo las xilografías son 49 , destacando algunas imágenes desarrolladas en perspectiva para escenarios teatrales (h. 67 r. ${ }^{\mathrm{o}}$ escena cómica; 69 r..$^{\mathrm{o}}$ escena trágica; y $70 \mathrm{v} .^{9}$ escena satírica, firmada con el anagrama "KD"). La portada es más sencilla que las grabadas para los libros tercero y cuarto, limitándose a una orla de tipo manierista en la que se incluyen algunos objetos alusivos a la Arquitectura: compás, plomada, escuadra..., todo ello rematado por la salamandra real francesa.

En el número cinco catalogamos la colección de las ediciones holandesas de los libros I-V que publicó en Amberes Pieter Coecke y su viuda. Coecke fue el introductor de las ideas arquitectónicas del Renacimiento italiano en los Países Bajos ${ }^{28}$. Su papel es el de divulgador que, como Jean Martín en Francia, traduce y edita los tratados más importantes que llegan a sus manos.

En 1539 Coecke edita en holandés un compendio de la obra de Vitrubio, basándose en el texto italiano de Cesariano (Como, 1521), con una tirada superior a los 650 ejemplares. El mismo año publica la tradución holandesa del libro

26. Ver nota 24.

27. LORBER, Maurizio: "I primi due libri di Sebastiano Serlio dalla struttura ipotetico-deduttiva alla struttura pragmatica”, en Sebastiano Serlio: Sesto Seminario... op. cit. págs. 114-125.

28. OFFERHAUS, Johannes: "Pierre Coecke et lîntroduction des traités d'architecture aux Pays-Bas”, en Les traités d'architecture de la Renaissance... op. cit. págs. 443-452. 
cuarto de Serlio, cuyo original había parecido en Venecia tan sólo dos años antes (1537). Desde entonces hasta la fecha de su muerte se dedicará a traducir y editar todos los libros de Serlio, labor que concluye su viuda.

Las traducciones francesas de Coecke encontraron la oposición de las publicadas por el propio Serlio, que tenía el privilegio de impresión y venta para toda Francia ${ }^{29}$.

Los diferentes libros de Serlio que Coecke y su viuda editaron, fueron publicados separadamente -excepto el I y II- formando unidades bibliográficas independientes. Sólo el hecho de que algún librero ${ }^{30}$ fuera acumulando parte de las ediciones para encuadernarlas como conjunto, hace que hoy aparezcan unitariamente reunidas en colecciones como la que catalogamos (Cat. n. .5 ).

En España los libros de Serlio conocen una traducción temprana, de enorme éxito y trascendencia, la realizada por el rejero y arquitecto Francisco Villalpando ${ }^{31}$ (c. 1510-1561), editada en Toledo en 1552, y posteriormente reimpresa en 1563 (cat. $n .^{\circ}$ ) y 1573 . En ella se incluyen los libros tercero y cuarto, los más importantes de la serie.

En la traducción española. posiblemente realizada antes de $1548^{32}$ y dedicada al príncipe Felipe (futuro Felipe II), se siguen las ediciones venecianas de 1537 y 1540 , de las que también se copian las ilustraciones. En el prólogo al lector Villalpando afirma estar trabajando en los libros primero y segundo, para su publicación, empresa que no se llevó a cabo. La traducción española es muy fiel al texto italiano y sólo de forma ocasional el autor comenta personalmente alguna de las afirmaciones de Serlio.

La influencia en el ambiente artístico español e hispanoamericano de este repertorio gráfico comentado fue enorme ${ }^{33}$. La normalización de los órdenes que aporta Serlio por vez primera en un libro impreso, fue aprovechada por Arquitectos de obra y de retablos que en sus realizaciones imitan fielmente o con varian-

29. Ibídem, pág. 446.

30. Ibídem, afirma que el grabador Cornelius bos tenía en 1542, 350 ejemplares de la traducción de Serlio.

31. Algunos datos biográficos sobre Villalpando en NIETO, Victor, MORALES, Alfredo J. y CHECA, Fernando: Arquitectura del Renacimiento en España: 1488-1599. - Madrid: Cátedra, 1989, págs. 204-205.

32. Según KUBLER, George en su introducción a la edición facsímil del texto de Serlio: Tercero y quarto libro de Architectura de Sebastian Serlio boloñes / ... traduzido de Toscano en Romance Castellano por Francisco de Villalpando arquitecto. Toledo: Juan de Ayala, 1552. (Valencia: Albatros, 1977 [col. Juan de herrera, 2]).

33. SEBASTIAN, Santiago: "La influencia de los modelos ornamentales de Serlio en Hispanoamérica", en Boletín del Centro de Investigaciones Históricas y Estéticas de la Universidad de Venezuela. V. 7 (1967), págs. 30-67. Jesús Miguel Palomero Páramo: "La influencia de los tratados de Serlio y Paladio en los retablos de Martínez Montañés" op. cit. págs. 503-525. 
tes los diseños serlianos. Por solo citar algunos entre los más cercanos, destacaremos la influencia ejercida sobre Hernán Ruiz II, Martínez Montañés, Juan de Arfe y fray Juan Ricci. Los impresores del área toledana copiaron con frecuencia las portadas del tratado de Serlio para enmarcar los títulos de sus publicaciones ${ }^{34}$.

La cuarta obra que catalogamos de Serlio es la edición veneciana de 1560 de su Extraordinario libro di architettura (cat. n.․ 7), publicado por vez primera en Lyon en 1551.

La obra se compone de un breve comentario, reunido al principio del libro, y de cincuenta láminas representando diferentes diseños de portadas: treinta rústicas y veinte "delicadas". En ellas Serlio se muestra claro defensor de los valores de libertad, inventiva, combinatoria y variedad que originan el estilo Manierista. Otra novedad importante es la de ejecutar las ilustraciones por medio de grabados calcográficos, que dan una mayor calidad y detalle a los diseños, los dibujos fueron preparados por el propio autor en manuscritos de los cuales conservamos, al menos, uno ${ }^{35}$. Este sistema de imagen ciudadosamente grabada y breve texto argumental fue sistemáticamente usado por tratadistas posteriores como Vignola y Labacco ${ }^{36}$.

El Libro Extraordinario gozó de una popularidad incluso mayor que la obtenida por el resto de los manuales de Serlio. Prueba de ello es la rapidez con el que se sucedieron sus ediciones.

Once ediciones (trece si consideramos separadas las bilingües como hace Bury ${ }^{37}$ ) en dieciocho años "no es un mal promedio", y explica las reiteradas citas que de este libro hacen arquitectos como Vedreman de Vries, Dieterlin y Hernán Ruiz II tanto en su obra escrita (tratados) como en la construida ${ }^{38}$.

En la edición que catalogamos (Venecia: Giovambatista \& Marchio Sessa, 1560) se incluyen algunas ilustraciones de carácter ornamental (grutescos) que

34. La copiarán los impresores Juan de la Plaza (Pedro Sánchez: Historia moral y Philosophica. Toledo, 1590) y usando la misma xilografía que en anterior Tomás Guzmán (Pedro Sánchez: Triángulo de virtudes Theologicas... Toledo, 1595). Véase Blanca García Vega: El grabado del libro español. - Valladolid: Diputación, 1984, 2 vol. T. I lám. 353 y 405 . T. II. n. 730 y 737.

35. Sę conserva este códice en la Stadtbibliothek de Augsburgo (sign. 2. ${ }^{\circ}$ Cod. 496), y ha sido estudiado por Johannes Erichsen: "L'Extraordinario Libro di Architectura: note su un manoscritti inedito”, en Sebastiano Serlio: Sesto Seminario... op. cit. págs. 190-195.

36. ZERNER, Henri: "Du mot à l'image: le rôle de la gravure sur cuivre", en Les traités d'architecture de la Renaissance... op. cit. págs. 281-294.

37. BURY, John Bernard: "Serlio: some bibliographical notes", en Sebastiano Serlio: Sesto Seminario... op. cit. pág. 101.

38. ZERNER, Henri: "Du mot à l'image: le rôle de la gravure sur cuivre", en les traités d'architecture de la Renaissance... op. cit. pág. 284. Y Pedro Navascués Palacio: "El Manuscrito de Arquitectura de Hernán Ruiz, el joven", en Archivo Español de Arte n." 175 T. XLIV (1971) págs. 295-321. 
no aparecen en las primeras ediciones francesas, lamentablemente algunas faltan en el ejemplar y otras están muy deterioradas por manchas de tinta (cat. n. 7 ).

\section{Antonio Labacco “Libro Apartenente all'Architettura” (1552)}

El libro de Antonio Labacco se nos presenta más como repertorio arqueológico de monumentos antiguos, que como tratado de arquitectura propiamente dicho. El autor proyectaba una obra más ambiciosa, donde lo antiguo y lo moderno se reuniesen coherentemente en un conjunto de imágenes comentadas representativas del lenguaje formal clásico. La compleja gestación editorial de la obra impidió que esta idea inicial se llevase a la práctica, incluyéndose tan sólo una obra de diseño moderno entre los grabados estampados. Puede, por tanto, ser integrada en el largo ciclo de estudios sobre las antiguiedades y monumentos de Roma que iniciándose en tiempos medievales con los Mirabilia Urbis Romae, se hará sistemático y científico con los textos y diseños de arquitectos y pintores como: Alberti, Giuliano de Sangallo, Rafael, Bramante, Antonio de Sangallo el joven y Baldassare Peruzzi.

Las láminas de la obra son ejemplos modélicos del esfuerzo realizado por un grupo de pintores y arquitectos que trabajan en Roma en el círculo de Rafael por desarrollar nuevo métodos de expresión gráfica arquitectónica. Junto al dibujo de proyecto el interés renacentista por los restos conservados de la antigüedad clásica generó auténticas campañas de levantamiento de planos y diseño de vistas ${ }^{39}$. Sangallo el joven, maestro de Labacco, dibuja con maestría algunos planos acotados, siendo el primero en usar coherentemente la proyección ortogonal que Rafael ya había descrito. Baldassare Peruzzi en sus diseños intenta combinar la planta y la representación del espacio interior por medio de la sección en perspectiva. Las experiencias de ambos en el medio gráfico fueron bien conocidas por Labacco, que las culmina en los diseños de su obra, en los cuales manteniendo la proyección ortogonal consigue imágenes unitarias de planta, alzado y sección ${ }^{40}$.

Il libro d'Antonio Labacco apartenente all'Architettura fue publicado por vez primera en 1552 (Roma: Casa nostra = A. Labacco). El propio autor confiesa editarla incompleta y con prisa por temor a que algún impresor "pirateara" su trabajo. Esta publicación original constaba de: hoja de título (grab. calc.); un folio con la dedicatoria y el prefacio; y 25 grabados en cobre de edificios, con

39. SAINZ, Jorge: El dibujo de arquitectura: teoria e historia de un lenguaje gráfico. Madrid: Nerea, 1990, págs. 84-100.

40. LOTZ, Wolfgang: la arquitectura del Renacimiento en Italia: estudios. Madrid: Hermann Blume, 1985, págs. 29-31. 
una hoja intercalada de tipografía antes de la gran lámina desplegable del puerto de Ostia. Once ilustraciones no llevan título y las cuatro finales no incluyen ningún texto. El comentario, cuando lo hay, aparece en la misma hoja del grabado, unas veces inciso en la plancha calcográfica y otras impreso tipográficamente. Todo ello nos habla de la provisionalidad de esta edición. En el mismo año 1552 salió una nueva versión con el texto de todas las láminas grabado en la matriz de cobre. A estas primeras ediciones les sucede un gran número de nuevas versiones, siempre con ligeros cambios. Las tiradas debían ser cortas en cada ocasión, existiendo numerosas variantes. Como dice Martín C. Perdue: "No hay dos copias iguales, y la historia y alcance de sus muchas impresiones no están del todo claras" ${ }^{41}$. El intento más completo de reseñar las diferentes ediciones fue el realizado por Thomas Ashby a principios de nuestro siglo ${ }^{42}$.

Algunos investigadores han señalado la obra de Labacco como inmediato precedente del tratado de Vignola ${ }^{43}$. Es la primera publicación, junto al Libro extraordinario de Serlio, editado en Lyon el mismo año de 1552, que utiliza la estructura de colección de grabados calcográficos de cuidado diseño con comentario incluido en él y casi nula presencia de la tipografía. Labacco y Vignola se diferencian de Serlio en el respeto que muestran al lenguaje clásico vitrubiano que ellos pretenden codificar. Vasari fue consciente de la importancia de estos tres libros, y los cita de forma conjunta en un apartado de su obra ${ }^{44}$; criticará las "herejías" de Serlio y alabará el respeto normativo y el sistema modular de Vignola.

Los grabados para el libro de Labacco fueron ejecutados por él mismo y por su hijo Mario, ayudados posiblemente por un grabador llamado Perugino. La portada realizada por Mario sigue un diseño del pintor Francesco Salviati, incluyendo alegorías de la Arquitectura y la Geometría. El estilo y técnica de estas

41. WIEBENSON, Dora (dir.): Los tratados de Arquitectura: De Alberti a Ledoux. op. cit. pág. 66 (redactado por Martín C. Perdue).

42. ASHBY, Thomas: "Il libro d'Antonio Labacco appartenente all'Architettura", en $L a$ Bibliofilia T. XVI (1914-15) págs. 289-309.

43. THOENES, Christof: "La regola delli cinque ordini del Vignola", en Les traités d'architecture de la Renaissance... op. cit. págs. 267-279. Ver pág. 274. También: ZERNER, Henri: "Du mot à l'image: le rôle de la gravure sur cuivre" op. cit. págs. 285-287.

44. "La dove, vedendo ridurre ogni in pessima maniera, Sebastiano Serlio bolognese, architetto, mosso da pietà, la intaglio in legno et in rame dua libri d'architettura, dove son fra l'altre cose trenta porte rustiche e venti delicate. Il qual libro è intitolato al re Arrigo di Francia. Parimente Antonio Abbaco ha mandato fuori con bella maniera tutte le cose di Roma antiche e notabili, con le lor misure fatte con intaglio sottile e molto ben condotto da... perugino. Né meno a in cio operato Iacopo Barozzo da Vignola architectore, il quale in un libro intagliato in rame ha con facile regola insegnato ad aggrandire e sminuire secondo gli spazii de cinque ordini d'architettura...". Cito a través de H. Zemer: op. cit. págs. 286-287. 
láminas arquitectónicas es el usado habitualmente por la escuela romana de grabado calcográfico, que había iniciado en las primeras décadas del siglo Marcantonio Raimondi.

\section{Pietro Cataneo "I Quattro Primi Libri di Arquitettura" (1554)}

Pietro Cataneo (1510-1569) forma parte de esa cadena de arquitectos-ingenieros sieneses, que expresan su formación constructiva escribiendo tratados ilustrados sobre el arte de edificar. El primer eslabón de la serie fue Mariano Taccola con sus obras: De ingeneis (1419) y De Machinis (1449), continuando en los escritos de figuras de mayor relieve como Francesco di Giorgio Martini, Baldassare Peruzzi y el propio Cataneo ${ }^{45}$.

El autor durante una corta estancia en Venecia entre 1553 y 1554 publica el tratado que ahora catalogamos: I quattro primi libri di architettura (Venecia: herederos de Aldo Manucio, 1554). La obra de Cataneo participa de la tendencia que continúa los estudios vitrubianos del siglo XV y principios del XVI desde el punto de vista práctico y renovador tal como habían hecho Francesco di Giorgio y Serlio ${ }^{46}$. Sus principales aportaciones son los capítulos que versan sobre topografía, urbanismo y fortificación, en los cuales se alude constantemente a su experiencia como arquitecto militar durante las guerras sienesas.

La ciudad pasa a ser el personaje principal del tratado, estudiándose su emplazamiento, planta y defensas, además de los edificios públicos y privados que en ella se deben construir ${ }^{47}$.

Cataneo justifica las nuevas teorías de fortificación en los requerimientos defensivos y ofensivos que impone la artillería, arte militar desconocido por los antiguos; la licencia de las normas vitrubianas es por tanto una necesidad derivada del progreso técnico.

El autor expondrá la moderna sistemática de la arquitectura de fortificación en los veinte capítulos del primer libro, ilustrando los diferentes modelos propuestos con quince xilografías de plantas y perspectivas de ciudades. En estas

45. SCAGLIA, Gustina: "The development of Francesco di Giogio's treatises in Siena", en Les traités d'architecture de la Renaissance... op. cit. págs. 91-97.

46. TAFURI, Manfredo: La Arquitectura del Humanismo. Madrid: Xarait, 1982, págs. 121-122.

47. Son significativas, como declaración de principios, las palabras del autor en la dedicatoria a Enea Piccolomini:

"La piu bella parte dell'Architettura certamente serà quella, che tratta delle città, doue piu moltiplicano gli huomini, \& fioriscono le notitie \& esercitii humani, le quali essendo modernamente offese dalle artiglierie, che non haueuano gli antichi; non serà presontione la mia, se io mostrerò di edificarle altrimente, per difenderle da quelle offese, alle quali essi non hanno potuto prouedere, per non hauerle hauute al tempo loro...". 
imágenes contemplamos: planos urbanos de trazado hipodámico que se adaptan a las murallas y baluartes de formas estrelladas o poligonales, perspectivas de muros en pronunciado talud, glacis y fosos, etc., todo lo necesario para obtener un sistema solidario de defensa.

Signo de modernidad en la obra que comentamos es el uso frecuente en sus ilustraciones (42 grabados xilográficos) de las vistas en perspectiva, método denostado por Alberti, pero que fue defendido y cada vez más utilizado por los arquitectos de la primera mitad del siglo XVI (Peruzzi, Serlio, Labacco, Vignola).

En 1567 Cataneo publicó en Venecia la segunda y última edición de la obra, añadiendo cuatro libros más a los que aparecieron en 1554. De esta forma el tratado adquiere carácter enciclopédico, abarcando de manera unitaria arquitectura civil y militar, razonamientos teóricos junto a consejos técnicos y soluciones estilísticas. En la segunda mitad del siglo XVI los estudios tenderán a la especialización, separando los diferentes campos de la ciencia arquitectónica: tratados de edilicia pública y privada (Palladio), frente a los libros de fortificación (Gerolamo Maggi, Iacomo Castriotto, F. De' Marchi, etc.) ${ }^{48}$.

\section{Andrea Palladio “I Quatto Libri dell'Architettura” (1570)}

Andrea Palladio (1508-1580) es probablemente el tratadista y arquitecto de época manierista mejor estudiado. La bibliografía sobre su figura y actividad se ha incrementado de forma considerable en los últimos treinta años ${ }^{49}$. La formación y biografía de este arquitecto es, por tanto, suficientemente conocida y aquí sólo ofreceremos un panorama de su labor teórica y de su interés por la ilustración gráfica arquitectónica.

Palladio en sus frecuentes viajes levantó planos de gran parte de los edificios romanos existentes. usó para ello la proyección geométrica plana, convenientemente acotada, este método de representación primaba la objetividad estructural de la construcción sobre valores perceptuales o de visualización del espacio. Es por tanto un sistema de recogida de información con criterios profesionales, por y para arquitectos, sin las concesiones pictóricas habituales en otros dibujos orientados hacia el público diletante.

48. WILKINSON, Catherine: "Renaissance treatises on military architecture and the science of mechanics" en Les traités d'architecture de la Renaissance... op. cit. págs. 467-476.

49. En este sentido se deben señalar los trabajos patrocinados por el Centro Internazionale di Studi di Architettura Andrea Palladio de Vicenza desde 1959 (Boletín anual). Además de estudios monográficos como los de James S. Ackerman (Palladio. Madrid: Xarait, 1987, 1. ed. 1966) y Lionello Puppi (Andrea Palladio. Milán: Electa, 1973); junto a los catálogos de dos importantes exposiciones: Mostra Palladiana (1973) y Palladio: la sua ereditá nel mondo, 1580-1980 (1980). 
Su experiencia arqueológica se plasmó en la publicación de Lantichitá di Roma (Roma: Vincenzo Lucrino, 1554) pequeño librito -curiosamente sin ilustraciones-, donde se describe con rigor topográfico la situación y características de los principales edificios de la Roma antigua.

La siguiente incursión de Palladio en el mundo editorial tendrá mayor trascendencia. El culto humanista veneciano Daniel Barbaro, amigo del arquitecto, le pedirá que ilustre la traducción que había realizado de los libros de Vitrubio. Por primera vez se unen la erudición filológica del sabio y la experiencia arqueológica de un arquitecto en la difícil empresa de restaurar texto e imágenes de la obra romana. El resultado de la colaboración fue la magnífica versión impresa por Francesco Marcolini en Venecia (1556), tal vez la más bella jamás realizada de los libros vitrubianos. Palladio en sus diseños sintetiza una larga tradición de descripción de edificios clásicos, utilizando con maestría los recursos gráficos más avanzados ${ }^{50}$.

La obra que le dio mayor fama, y en la que recoge todos los conocimientos y experiencias de una vida dedicada a la arquitectura será I quattro libri dell' Architettura. El manuscrito original circulaba ya en 1555, y Giorgio Vasari lo leyó hacia 1566. Palladio tardaría aún varios años en publicarlo; tras revisar el texto e ilustraciones se lo entregó al tipógrafo Domínico de Franceschi, especialista en este tipo de libros de contenido artístico con numerosos grabados, quien imprimió la obra en 1570 .

Parece que el propio Palladio pretendió ampliar el tratado con un quinto libro. En el proemio al libro tercero afirma: "Per la qual cosa in questo libro, nel quale io dò principio alle mie antichità, $\&$ ne gli altri (libri) che piacendo iddio seguiranno...". En 1581, muerto el maestro, su hijo Silla pretende reimprimir el libro "ampliati di molti edifici si antichi come moderni", años después en 1588 aún insiste en este propósito ${ }^{51}$.

Palladio en el prólogo del primer libro pone por guía de toda buena arquitectura a Vitrubio, reconociendo a su vez el valor testimonial de las ruinas romanas como fuente de modelos para el arquitecto, tal como había señalado Alberti. A pesar de estas citas eruditas el tratado palladiano no es una obra de especulación humanística, la intención pedagógica y de autopublicidad orientan el libro hacia el terreno práctico. Este hecho se acentúa con la sobriedad casi lacónica de sus textos y sobre todo en el importantísimo papel de las ilustraciones. Estas son muy diferentes de las que habían popularizado los tratados romanos de mediados

50. PUPPI, Lionello: Andrea Palladio, op. cit. págs. 284-285. También WIEBENSON, Dora (dir.): Los tratados de Arquitectura: De Alberti a Ledoux, op. cit. n. ${ }^{9}$ I-21 págs. 68-71 (redactado por David Rosand). Y Jorge Sainz: El dibujo de arquitectura. op. cit. págs. 23-24 y 96.

51. PUPPI, L.: Andrea Palladio, op. cit. pág. 285. 
de siglo (Labacco y Vignola), no utiliza las costosas planchas calcográficas, sino las humildes xilografías, multiplicando el número de diseños muy por encima de los que ofrecen las obras romanas. Más significativo es su rechazo por la vista en perspectiva (tal vez siguiendo la opinión de Alberti), limitando sus dibujos a plantas, alzados y secciones representados en proyección plana. Sabemos que Palladio diseñó las ilustraciones pero no trabajó personalmente en la talla de las matrices, y así en el libro segundo (pág. 22) se disculpa por no ofrecer la planta de un edificio: "per non hauere potuto farlo intagliare à tempo".

El interés que demuestra Palladio por realizar una síntesis no dogmática del lenguaje clásico, su maestría en el arte de componer volúmenes y combinar tipologías espaciales; unido todo ello a un gran pragmatismo, que le permite adaptar las construcciones a los programas ideológicos y económicos del patriciado véneto, son algunos de los factores que explican el éxito alcanzado por su arquitectura $^{52}$.

\section{Cristóbal de Rojas “Teórica y Práctica de Fortificación...”(1598)}

Cuando comentamos las ediciones españolas de los tratados de Alberti (Madrid: Alonso Gómez, 1582. Cat. n.․ 1) y Vitrubio (Alcalá de Henares : Juan Gracian, 1582. Cat. n. ․ 3), afirmábamos que su publicación se debió en parte a la reciente fundación en Madrid de la Academia de Matemáticas y Arquitectura civil y militar. La obra que ahora estudiamos: Teórica y práctica de fortificación, conforme las medidas y defensas destos tiempos... del capitán e ingeniero militar Cristóbal de Rojas ${ }^{53}$, fue el resultado de las clases impartidas por el autor en la Academia madrileña. El mismo Rojas nos informa en el prólogo del libro como Francisco Arias de Bobadilla, Conde de Puñonrostro, le convenció para dictar algunas lecciones de arquitectura militar y luego publicarlas apoyado por los consejos de Juan de Herrera y Tiburcio Espanoqui. La obra forma parte del programa de publicaciones de la institución, que incluía también libros de geometría y perspectiva.

Conocemos bien la biografía de Cristóbal de Rojas gracias, sobre todo, al estudio que Eduardo de Mariátegui realizó sobre él, nos centraremos pues aquí en su faceta como teórico y divulgador de la arquitectura militar.

52. TAFURI, Manfredo: La Arquitectura del Humanismo, op. cit. págs. 70-72.

53. Existe una edición facsímil de los tratados de Rojas, con introducción crítica de Ramón Gutiérrez (Cristóbal de Rojas: tres tratados sobre fortificación y milicia. Madrid: CEHOPU, 1985). Se incluye con acierto en esta publicación el estudio biográfico que Eduardo de Mariátegui realizó sobre el ingeniero: El capitán Cristóbal de Rojas ingeniero militar del siglo XVI. Madrid: Imprenta del Memorial de Ingenieros, 1880 (Madrid: CEHOPU, 1985). 
El afán por trasmitir sus conocimientos profesionales llevó a Cristóbal de Rojas a redactar tres manuales sobre el arte de la fortificación y la milicia; dos se llegaron a imprimir en vida del autor quedando el tercero inédito. El más importante y cabeza de la serie es la Teórica y práctica de fortificación (Madrid: Luis Sánchez, 1598) ${ }^{54}$. Esta obra participa de la tendencia hacia la especialización de la tratadística arquitectónica de la segunda mitad del siglo XVI. La fortificación moderna nace de necesidades concretas de defensa que impone el nuevo armamento artillero, como ya había señalado Pietro Cataneo. Los principios teóricos y sobre todo la práctica constructiva que desarrolla la hizo separarse cada vez más de la arquitectura civil.

El manual de Rojas fue el primero de esta materia que se publicó en España, es cierto que antes que él algunos compatriotas escribieron sobre el tema de la fortificación y la poliorcética pero sus obras quedaron manuscritas ${ }^{55}$.

El tono manualístico predomina en toda la obra y se acentúa al optar por un tipo de exposición casuística, directamente apoyada en su experiencia pedagógica y edilicia.

Junto al texto en esta obra son de gran importancia las ilustraciones, sin las cuales no se comprenderían muchos aspectos de la narración. Los numerosos grabados xilográficos, algo toscos en su ejecución, se intercalan en los párrafos que requieren explicación gráfica. El autor incluirá algunos de sus proyectos originales, así: la propuesta de fortificación de Cádiz (h. 49 v. ․o -50 r.ำ), donde aparece la idea de Espanoqui de una ciudadela en el frente que emboca la bahía. También nos muestra el tipo de baluarte inventado por él, que se caracteriza por sus aristas mixtas, vivas en la base y redondeadas en la parte superior (h. 75 v.. 76 r. ${ }^{\circ}$ ). En ambos casos se observa un uso muy deficiente de la perspectiva.

Rojas demuestra conocer las modernas teorías italianas de fortificación con baluartes ${ }^{56}$, aportando experiencias e ideas propias a la sistemática defensiva de la ciudad. Como Vitrubio, defiende la dualidad teoría-práctica en la arquitectura, propugnando un aprendizaje riguroso de la Geometría euclidiana y de la aritmética, pero sin olvidar que la poliorcética es en gran medida un arte empírico, donde las tipologías perduran o cambian en virtud de su eficacia. El decoro de la construcción militar será pues la correcta adecuación de la estructura defensiva a la capacidad ofensiva del enemigo.

54. Los otros escritos de Rojas tuvieron menor trascendencia y son: el Sumario de la milicia antigua y moderna (Cádiz, 1607), inédito en su tiempo; y el Compendio y breve resolución de fortificación conforme a los tiempos presentes... (Madrid: Juan de Herrera, 1613).

55. Ver GUTIERREZ, Ramón: Tres tratados... op. cit. pág. 12-14.

56. Rojas cita en su tratado a los principales autores italianos sobre fortificación: Galeazzo, Busca, Girolamo Maggi, Castriotto, Lanteri, Tetti y Girolamo Cataneo. 


\section{Catalogo}

\section{$\begin{array}{ll}\text { NN. } 1 \text { ALBERTI, Leone Battista } & \text { R. 12, T. } 27\end{array}$}

Los diez libros de Architectura de Leon Baptista Alberto / Traduzidos de latin en romance. - [Madrid] : En casa de Alonso Gomez impressor de su magestad. [impreso a costa de Francisco Lozano], 1582.

[4] h., 343 [i.e. 347$]$ p., [19] h. ; $4^{\circ}(20 \mathrm{~cm}$.)

Cfr.: Bonet, 275. CC s. XVI-A, 600. Palau, 5194. Bustamante, 2378.

[]$^{4}, A-Z^{8}, 2 a^{8}, 2 b{ }^{1}$. - Lug. de imp. tomado de prelim. - Nombre de ed. tomado del privilegio. - H. imp. por ambas caras. - Error de pag. no afectando al texto. - 41 lín. numeradas cada cinco en el margen interno. - L. hum. min. redonda, min. cursiva en dedic. y títulos. - Port. con grab. xil. arqu. - Cap. dec. - Tabla de capítulos y repertorio alfabético entre $Y_{7}-2 b_{1}$ - Enc. Hol., con hierros dorados en lomo, no orig., s. XIX. Recortado. - Expurgado en pág. 220 (lín. 27-41) y 221 (lín. 1-12). - An. Mss.: en v. ${ }^{\circ}$ de la cubierta "D. Z." y "1568".

R. 2367 (1931)

Bib.: Sevilla B. U., Cádiz B. P., Madrid B. N., Madrid B. Palacio, Salamanca B. U., Santiago B. U., Toledo B. P., Granada B. U.

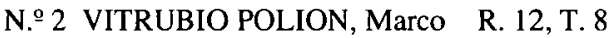

M. Vitruuii Pollionis de Architectura libri decem / Accesserunt Gulielmi Philandri Castilionii, ciuis romani annotationes castigatiores, \& plus tertia parte locupletiores. Adiecta est epitome in omnes Georgij Agricolae de mensuris et ponderibus libros / Eodem autore. - Omnibus omnium editionibus longè emendatiores, collatis veteribus exemplis. Lugduni : Apud Ioan Tornaesium, 1552.

[8] h., 447 p., [28] h., [1] h. de lám. pleg. : il. (grab. xil.) ; 4. ${ }^{\circ}(25 \mathrm{~cm}$.).

Cfr.: Adams, V-908. Bustamante, 1007. CC s. XVI - V-Z, 1259. Wiebenson, I- 17.

$A^{4}, A^{4}, a-z^{4},[]{ }^{1}, A-Z^{4}, 2 a-2 r^{4}$. - Guillaume Philander comentarista filológico del texto de Vitrubio. - H. imp. por ambas caras. - Grab. xil. intercalados en el texto. - Lám. plegada fuera de texto entre p. 184-185. - Grab. xil. retrato de G. Philandro, en A 4 v.. 2.. serie. - Marca del imp. en port. y lema en $2 r_{4} v .^{.}$- Cap. y orlas dec. - Tabla de capítulos en

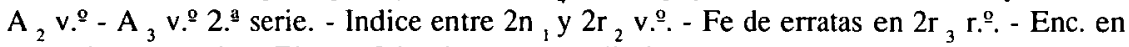
pasta, lomo en tela. - Ejemp. falto de port. y preliminares. - Tít., mención de responsabilidad y datos de publicación tomados de otro ejemplar de la misma ed. y tirada : Madrid B.N. R-15154. - An. mss. : En $v^{0}$ de cubierta : "125. / falto de portada / impreso en Roma 1512."; en $v^{o}$ de guarda inicial : "AZ".

Bib.: Burgos B. P., Madrid A.B.A., Madrid B. N., Salamanca B. U. 


\section{$\begin{array}{ll}\text { NN. } 3 \text { VITRUBIO POLION, Marco } & \text { R. 13, T. } 27\end{array}$}

De Architectura : diuidido en diez libros / M. Vitruuio Pollion ; traduzidos de latin en castellano por Miguel de Vrrea architecto ; y sacados en su perfectio por Iuan Gracian impressor vezino de Alcala. - Impresso en Alcala de Henares : por Iuan Gracian, 1582.

178 [i.e. 138], [5] h. : il. (grab. xil.); Fol. $(30 \mathrm{~cm}$.)

Cfr.: Adams, V-919. Bonet, 706. Bustamante, 2437. CC s. XVI - V-Z, 1272. Palau, 371184. Wiebenson, I-27.

A-Z ${ }^{6}, b^{2}, a^{6}$. - El nombre del autor precede al tít. - H. imp. por ambas caras. - H. $a_{6}$ en bl. - Error tip. de fol.: h. 61 núm. como 66 y h. 121-138. - Explicaciones a las il. en glosas marginales. - 39 lín. - L. hum. min. redonda y min. cursiva en prol. capítulos y glosas. - Port. con esc. xil. - Numerosos grab. xil. intercalados en el texto. - Inic. dec. Tabla de materias en $\mathrm{b}_{1}-\mathrm{b}_{2}$ - Vocabulario en $\mathrm{a}_{1} \mathrm{a}_{5}$ - Enc. en piel, con hierros dorados en lomo, cortes tintados en rojo. - Faltan las $h . b_{1}-b_{2}$, con la tabla de materias (vid. ejemp. Madrid B. N. U-8567). - An. mss. son principalmente apostillas marginales corrigiendo erratas.

R. 5220 (2-1-1941)

Bib.: Madrid A.B.A., Madrid B. Lázaro, Madrid B.N., Madrid B. Palacio, Madrid B. Senado, Madrid C.O.A.N.

\section{N.. 4 SERLIO, Sebastiano R. 7, T. 19}

Il primo [- secondo] libro d'Architecttura di Sabastiano Serlio, Bolognese = le premier [- second] liure d'Architecture de Sebastian Serlio, Bolognois / mis en langue francoyse par Iehan Martin secretaire de monseigneur le reuerendissime cardinal de Lenoncourt. - A Paris : de l'imprimerie de iehan Barbé, 1545.

[4], 74, [1] h. : il. (grab. xil.) ; Fol. (34 cm.)

Cfr.: CC. s. XVI-S, 1151. Bustamante, 714.

$2 a^{4}, a-h^{8},[]^{1}, i^{10}\left(b_{3}\right.$ aparece como $\left.a_{3}\right)$. - Texto bilingüe. - Imp. tomado del colofón en h. $i_{10} v$. . - - Fecha completa en colofón: "le vingt deuxiesme iour d'Aoust. M.D. quarante cinq.". - H. imp. por ambas caras. - H. de grab. intercalada entre $i_{3}$ e $i_{4} \sin$ seguir serie de numeración ni en sig. tip., su v. ํ en bl. - Error de fol., no afectando al texto: h. 18 núm. como 20 . - L. hum. min. cursiva para el texto italiano y min. redonda para el francés. - Port. con orla grab. xil. - Numerosos grab. xil. de diseños geométricos y perspectivas arq. - Emblema del imp. sobre el colofón. - Cap. dec. - Contiene:

"Le premier liure de geometrie = Il primo libro di geometria".

"le second liure de perspectiue = Il secondo libro di perspettia (sic)". 
Fe de erratas en $2 a_{4}$ r.o, al pie. - Enc. Hol. - Deteriorado sin afectar a texto, restauración antigua. - Falta h. 24. - An. mss.: en v. ${ }^{\circ}$ de port.: "este libro es de Francisco Moreno".

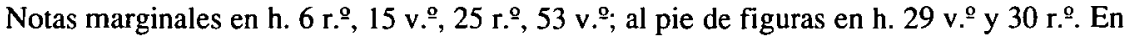
h. 23 v. 18 lín. en castellano traduciendo las primeras 19 lín. del texto italiano del segundo libro. En h. 74 v.. cuentas matemáticas.

R. $4576(15-1-1938)$

Bib.: Toledo B.P.

$\begin{array}{lll}\text { N.. } 5 \text { SERLIO, Sebastiano } & \text { R. 7, T. } 17\end{array}$

[Dat eerste [- vijfsten] boeck van Architecturen Sebastiani Serlij...]. - Antuerpen, 1546-1553.

1 v. : il. (grab. xil.) ; Fol. ( $36 \mathrm{~cm}$.)

[Den eerste boeck]: [Dat eerste boeck der Architecturen Sebastiani Serlij : tracterende van Geometrien / wten italiaensche in duytschen ouergesedt duer Peeter Coeck van Aelst schildere. - Antuerpen : Mayken Verhust, 155-]. - XIV h. - A-C ${ }^{4}, \mathrm{D}^{2}$. - Tít. tomado del colofón. - Puede ser 1.. (1553) 6 2. a (1558) ed. holandesa. - Datos de imp. tomados de J. B.

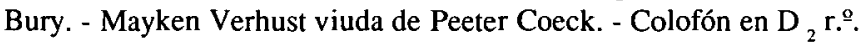
- Falto de port. y siete primeras h.

[Den tweede boek]: Den tweden boeck van Architecturen Sebastiani Serlij : tracterende van perspectyuen, dat is het insien duer tvercorten / ouergesedt wten italiaensche in nederlandts duer Peeter Coeke van Aelst doen ter tijt schildere der K. Maiesteyt. - Nu eerst wt laten gaen. - Gedruct inde vermaerde coopstadt van Antuerpen : duer Mayken Verhust weduwe des seluen Peeters voers, 1553. - XXVII h. - A-G ${ }^{4}$ - Es 1. ${ }^{a}$ ed. en hol. - Colofón en $\mathrm{G}_{3}$ v. ${ }^{\circ}$ - Falta última h. $\left(\mathrm{G}_{4}\right)$.

[Den derde boeck]: Die aldevermaertste antique edificien va temple, theatre, anphiteatre, palaisen, therme, obelisce, brugge, arche triuphal, ec., bescreue en gefigureert met haren gronde en mate oock de plaetsen daerse staen en wiese dede make. - Ghedruct inde vermaerde coopstadt van Hantwerpen : duer Peeter Coeck van Aelst..., by Gillis van Diest boeckprentrer, 1546 in april. - LXXIIII h. - A-R ${ }^{4}, \mathrm{~S}^{6}$. - $1 .^{\mathrm{a}}$ ed. en hol. - Datos de imp. tomados del colofón. - Colofón con registro tip.: "A-S alle zünt duernen vehaluen $S$ eens triteme" en $S_{6} v$. .

[Den vierde boeck]: Reglen van Metselrijen op de vijue manieren van edificien te wetene thuscana, dorica, jonica, corinthia en composita : ende daer by gesedt die exemplen vanden antijquen, die in dmeeste deel met de leeringe van Vitruuio ouercommen. - Met noch toegesedtte figueren 
die int eerste niet en waren ende sommige texten vanden aucteur gebetert hieroock by gesedt. - Gedruct Thantwerpen ; duer Peeter Couck van Aelst, 1549. - LXXII h. - A-S ${ }^{4}$ - 2..$^{\mathrm{a}}$ ed. en hol. - Datos

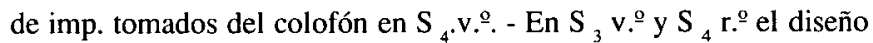
del alfabeto capital romano por $P$. Coeck.

[Den Vijften boeck]: Den vijften boeck van Architecturen Sebastiani Serlij: inden welcken van diuersche forme der templen getracteert wordt nae de maniere vanden antijken ende oock diemende voer de kerstenen / ouergesedt wten italiaensche in nederlandts duer Peeter Coeke van Aelst... - Nu eerst wt laten gaen. - Gedruct inde vermaerde coopstadt van Antuerpen : duer Mayken Verhulst..., 1553. - XVI h. - A-D ${ }^{4}$. - Colofón en $\mathrm{D}_{4} \mathrm{r} . \stackrel{\mathrm{g}}{\text {. }}$

Cfr.: Dora Wiebenson, I-12.

Obra sin tít. colectivo. - Peeter Coeck es el traductor y editor de la obra, sólo pudo imprimir en vida el libro IV, su viuda y Gillis van Diest editaron los restantes. - Los libros se imprimieron en Amberes entre 1539 y 1558 en sucesivas ed. - Cinco libros en 1 v. Cada libro con port., colofones y pag. independientes. - L. got. - Numerosos grab. xil. de arq. intercalados en el texto. - Cap. dec. - Enc. hol., no es la orig. - Mal enc. el libro I se ha situado al final tras el V. - An mss.: Lib. II: h. 10 r. " "Juan Perez", "festimado"; h. 13 v. "Joseph (+) Fernández"; h. 14 r.o "carminha", "Manoel" [Fernández?]. Lib. III: h. 27 v. "Joseph (+) Fernández". Lib. IV: h. 32 v. "octubre". Lib. I: h. 9 v.. "Manuel Saiz Pardo maestro de obras [del] Cabildo costo 120 reales". h. 12 r. "obalo encadenado", "hochavo por seis". En la h. final de guarda r.. , textos con las firmas de "Domingo Rodrigues del Castilo", "Josef Corttes deel Valle" y Santiago Peres; en el v.o texto francés que indica que el libro pudo pertenecer al conv. de Sta. María de la Sisla en Toledo.

R. 7872 (1-6-1949)

Bib.: Madrid B.N.

\section{$\begin{array}{lll}\text { N. } 6 \text { SERLIO, Sebastiano } & \text { R. 7, T. } 20\end{array}$}

Tercero y quarto libro de Architectura de Sebastian Serlio Boloñes: En los quales se trata de las maneras de como se pueden adornar los edificios : con los exemplos de las antiguedades / Traduzido d toscano en lengua castellana, por Francisco de Villalpando, architecto. - [2. ed.]. - Con licencia impresso en Toledo : en casa de Ioan de Ayala, 1563.

LXXX, LXXVII [i.e. 74] h. ; il. (grab. xil.); Fol. (34 cm.)

Cfr.: Bonet, 625. Bustamante, 1504. CC s. XVI-S, 1165. Palau, 309580.

$A-V^{4}, A-T^{4}$. - En port. del lib. cuarto, tít.: "Libro quarto de Architectura de Sebastian Serlio Boloñes: En el qual se tratan las cinco maneras de como se pueden adornar los 
edificios, que son; Toscano, Dorico, Ionico, y Corinthio, y Compuesto : con los exemplos de las antiguedades, las quales por la mayor parte se conforman con la doctrina de Vitruuio". - Ed. tomada de Bonet Correa n.․ 625. - Imp. tomado del colofón del lib. tercero y de la port. del cuarto. - H. imp. por ambas caras. - Errores tip. en fol. - L. hum., min. y may. redonda. - Port. a dos tintas con grab. xil. arq., se repite en port. del lib. cuarto. - Numerosos grab. xil. intercalados en el texto. - Inic. dec. - Colofón en orla manierista en $\mathrm{V}_{4}$ v. ‥ - Enc. en piel con hierros dorados en lomo. Corte tintado. - Ejemp. falto por el final, falta h. LXXVII ( $\mathrm{T}_{1}$ ) del lib. cuarto. - An. mss.: en v. ${ }^{\circ}$ de guarda inicial "Este libro es muy raro y apreciable, y vale (recortado)". En Port. nombre casi borrado, ilegible. En r. ${ }^{2}$ de h. LVI $\left(\mathrm{O}_{2} \mathrm{r}^{\circ}{ }^{\circ}\right)$ del libro cuarto "esta es la mejor". En guarda final " 60 ".

R. 4579 (15-1-1938)

Bib.: Sevilla B.U., Madrid B.N., Salamanca B.U.

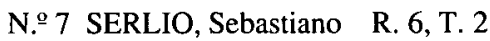

Extraordinario libro di Architettura di Sebastiano Serlio, architetto del Re Christianissimo : nel quale si dimostrano trenta porte di opera rustica mista con diuersi ordini \& uenti di opera dilicata di diuerse specie con la scrittura dauanti, che narra il tutto. - In Venetia : appresso Giouambattista, \& Marchio Sessa fratelli, 1560.

[6] h. XXX, XX, 16 h. de lám. : il. (grab. calc.); Fol. (41 cm.)

$\mathrm{A}^{6},[]^{66}$ (las láminas forman duernos). - H. de texto imp. por ambas caras. - L. hum. min. redonda. - 66 grab. calc. a buril, núm. arq. (portadas y diseños dec. de grutesco). En algunos figura la letra R. - Marca del imp. en port. - Inic. dec. xil. - Enc. en perg. - Ejemp. incompleto, faltan las h. 5, 6, 10-13 de la última serie, representando grutescos y diseños decorativos. - Lám. 1-3 de grutescos deterioradas por manchas de tinta. - An. mss.: En cubierta r. "Sebastiano Serlio Robira (...); en v.o sign. antigua "60/30". En port. sign. antigua " $32-5$ ".

R. 5980 (6-11-1944)

\section{N.. 8 LABACCO, Antonio R. 9, T. 5}

Libro d'Antonio Labacco appartenente a l'Architettura : nel qual si figurano alcune notabili antiquita di Roma. - Impresso in Roma : in casa nostra, 1559.

36 [i.e. 35], [1 bl.] h. : principalmente il. (grab. calc.) ; Fol. (41 cm.)

Cfr.: Adams, L-1. CC s. XVI-L-LL, 1.

[] ${ }^{36}$. - Hay diferentes estados de esta edición. - Datos de publicación tomados de preliminares, h. [] ${ }_{2}$ r. . - - Las h. de lám. van numeradas como h. - H. imp. por ambas caras en texto. - La H. [] ${ }_{36}$ en bl. - La h. 30-31 ([ [ $]_{30}$ ) plegada. - L. hum. cursiva en texto, hum. 
bastarda en grabados. - Port. grab. arq. - 26 grb. calc. a buril, arq. - Incluye privilegios papales (por motu propio) de paulo III, Julio III y Paulo IV. - Enc. en perg., corte tintado. - Los pliegos mal ordenados al encuadernarse: el pliego de las h. [7]-8 va entre la h. 4 y 5 , y el de las h. 29-30 y 31 se ha situado al final. - H. 9 recortada. - Ejemp. incompleto, falta h. 7 en donde va la mitad del grab. que representa la planta del templo en el foro de Trajano. - Ex-libris estampillado; "Aloysii Segalá Estalella" en port., sobre él, sello: "Regalado a la Facultad de Filosofía y Letras".

R. 2219 (1931)

Bib.: Salamanca B.U.

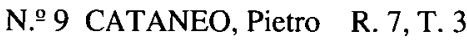

I quattro primi libri di Architettura di Pietro Cataneo Senese : nel primo... - In Vinegia : in casa de figliuoli di Aldo, 1554.

[2], 53, [2] h. : il. (grab. xil.) ; Fol. (35 cm.)

Cfr.: Adams, C-1024. CC s. XVI-C, 1191. Index Aur. VII, p. 153.

[]$^{2}, A-N^{4}, \mathrm{O}^{3}\left(\mathrm{~L}_{2}\right.$ aparece como $\left.\mathrm{I}_{2}\right)$. - Datos de publicación tomados del colofón. H. imp. por ambas caras. - Colofón, con el registro tipográfico: "A-O tutti sono duerni" en $\mathrm{O}_{3}$ r. . - - L. hum. min. redonda. - Numerosos grab. xil. arq. intercalados en el texto. - Cap. dec. xil. - Marca del imp. en port. y en $\mathrm{O}_{3}$ v.... - Indice en $\mathrm{O}_{2}-\mathrm{O}_{3}$. - Contiene:

"Nel primo de'quali si dimostrano le buone qualità de'siti, per l'edificationi delle città \& castella, sotto diuersi disegni:"

"Nel secondo, quanto si aspetta alla materia per la fabrica:"

"Nel terzo si veggono varie maniere di tempii, \& di che forma si conuenga fare il principale della città: \& dalle loro piante, come ancora dalle piante delle città \& castella, ne sono tirati gli alzati per ordine di prospettiua:"

“Nel quarto si dimostrano per diuerse piante l'ordine di piu palazzi \& casamenti, uenendo dal palazzo regale $\&$ signorile, come di honorato gentilhuomo, sino alle case di persone priuate."

Enc. Hol. - Parte inferior de la port. recortada. - An. mss.: En port. "DZ". En última h. $\left(\mathrm{O}_{3}\right.$ v.. ) "N. .256 ".

R. 4577 (15-1-1938)

Bib.: Madrid B.N., Salamanca B.U. 


\section{$\begin{array}{ll}\text { N.o } 10 \text { PALLADIO, Andrea } & \text { R. 7, T. } 25\end{array}$}

I quattro libri dell' Architettura di Andrea Palladio : ne' quali, dopo un breue trattato de'cinque ordini et di quelli auertimenti che sono piu nesesarij nel fabricare, si tratta delle case priuate, delle vie, de i ponti, delle piazze, de i xisti, et de'tempij. - In Venetia : appresso Dominico de Franceschi, 1570.

67,78, [2 bl.], 46, [2], 128 [i.e. 134], [2 bl.] p. : il. (grab. xil.) ; Fol. $(30 \mathrm{~cm}$.)

Cfr.: CC. s. XVI. L-LL, 336-337. Wiebenson, I-27.

$\mathrm{A}^{2}$, B-I ${ }^{4}, 2 \mathrm{~A}-2 \mathrm{~K}^{4}, 3 \mathrm{~A}-3 \mathrm{~F}^{4}, 4 \mathrm{~A}-4 \mathrm{R}^{4}$. - Colofón. - La h. $2 \mathrm{~K}_{4}$ y $4 \mathrm{R}_{4}$ en bl. - Error en sign. tip.: $4 \mathrm{~F}_{1}$ aparece como $4 \mathrm{E}_{1}$. - Error de pag. no afectando a texto. - L. hum. min. redonda. - Port. grab. xil., se repite en cada libro. - Numerosos grab. xil. arq. intercalados en el texto. - Marca del imp. en el v. ${ }^{\circ}$ de h. $4 \mathrm{R}_{3^{*}}$ - Cap. dec. - Contiene:

"Il primo libro... [si tratta della preparatione della materia, e de'cinque ordini]".

"Il secondo libro...: nel quale si contengono i disegni di molte case ordinate da lui dentro, e fuori della città, et i disegni delle case antiche de'Greci, et de'Latini'.

"Il terzo libro.... nel quale si tratta delle vie, de'ponti, delle piazze, delle basiliche, e de xisti".

"Il quarto libro...: nel qual si descriuono, e si figurano i tempij antichi, che sono in Roma, et alcuni altri, che sono in Italia, e fuori d'Italia".

Enc. imitación de perg. - P. $2 \mathrm{I}_{4}-2 \mathrm{~K}_{4}$ deterioradas afectando al texto, restauradas. - An. mss.: En port.: "N.. 14". En libro I, p. $\mathrm{B}_{2}$ r. ${ }^{\circ}$, notas marginales. En r. ${ }^{\circ}$ guarda inicial, sign. antigua: "2-4".

R. 2359 (1931)

Bib.: Salamanca B.U., Madrid A.B.A., Barcelona B.U.

\section{N.. 11 ROJAS, Cristóbal de R. 15, T. 6}

Teorica y practica de fortificacion, conforme las medidas y defensas destos tiempos: repartida en tres partes / por el capitan Christoual de Rojas, ingeniero del rey nuestro señor. - En Madrid : por Luis Sanchez, 1598

[4], 106 [i.e. 107], [1] h. : il. (grab. calc. y xil.)

Cfr.: Bonet, 815. CC s. XVI-Q-R, 1237. Palau, 275769.

[]$^{4}, \mathrm{~A}-\mathrm{H}^{6}, \mathrm{I}^{2}, \mathrm{~K}-\mathrm{N}^{6}, \mathrm{O}^{2}, \mathrm{P}-\mathrm{S}^{6}, \mathrm{~T}^{4}, \mathrm{~V}^{2}, \mathrm{X}^{2}$. - H. imp. por ambas caras. - Error de fol. sin afectar a texto: la h. 6 num. como 3 y la 107 como 106. 36 lín. - L. hum. min. redonda. - Port. grab. xil. arq. - Grab. calc. en v. ${ }^{9}$ de []$_{4} .:$ "Pedro Roman pintor f. 1592", representando el retrato del autor. - Numerosos grab. xil. intercalados en el texto, sobre 
arq. militar y geometría. - En I , v. ${ }^{\circ}$ y I ${ }_{2}$ r. ${ }^{\circ}$ vista de la ciudad de Cádiz y su proyecto de fortificación. - Orlas, Cap. dec. - Tabla de materias en $X_{2}$. Enc. perg., es la orig. restaurada. - Tít., mención de responsabilidad y datos de publicación tomados de otro ejemp. de la misma ed. (Sevilla B.U. est. 3167 n. ${ }^{2}$ 195). - Falto de port. y de las h. $3,4,16,18,26$, 59, 60, 106 (i.e. 107). - An. mss.: "hautor Franco. Ramirez en Cordova" en el retrato de

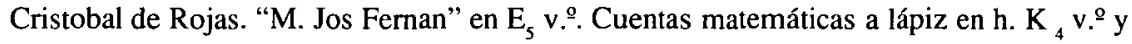
$\mathrm{K}_{5} \mathrm{r} . \stackrel{\mathrm{o}}{\mathrm{*}}$.

R. 7729 (4-3-1949)

Bib.: Sevilla B.U., Madrid B. Lázaro, Madrid B.N., Madrid B. Palacio. 